\title{
Ser lo que quieras: la libertad ontológica en Plotino y Gregorio de Nisa*
}

\author{
Francisco Bastitta \\ UNIVERSIDAD DE BUENOS AIRES \\ CONSEJO NACIONAL DE INVESTIGACIONES CIENTÍFICAS Y TÉCNICAS \\ fbastitta@conicet.gov.ar
}

Resumen: A mediados del siglo XX, Jérome Gaïth señalaba la posible influencia de Enéadas VI 8 (39) de Plotino sobre la teoría de la voluntad divina de Gregorio de Nisa. En ese tratado, a pesar de ser consciente de la impropiedad de todo lenguaje para describir lo Uno, Plotino le atribuye los clásicos distintivos del obrar humano: voluntad, libertad, autodeterminación, aunque elevados al grado absoluto. En el presente estudio analizaremos la recepción y transformación de esta teoría en el Niseno y sus corolarios antropológicos, en los que extiende la virtualidad de la libertad humana al plano ontológico.

Palabras clave: Trinidad, Antropología, Voluntad, Decisión, Imagen, Indeterminación.

Abstract: In the mid-twentieth century, Jérome Gaith drew attention to the possible influence of Plotinus' Enneads VI 8 (39) on Gregory of Nyssa's theory of Divine will. In this treatise, despite being aware of the inappropriateness of all language to describe the One, Plotinus ascribes to it the classical traits of human action: will, freedom, self-determination, though raised to an absolute degree. In the present study we will analyse the reception and transformation of this theory in Nyssen and its anthropological corollaries, in which he extends the virtuality of human freedom to an ontological level.

Keywords: Trinity, Anthropology, Will, Decision, Image, Indetermination.

* La investigación para este trabajo comenzó en el marco de mi proyecto de doctorado en Filosofía en la Universidad de Buenos Aires, bajo la dirección de la Prof. Claudia D'Amico y la codirección del Prof. Pablo Cavallero, y gracias a dos becas de posgrado del Consejo Nacional de Investigaciones Científicas y Técnicas (CONICET) de Argentina. Una versión preliminar fue presentada en el X Seminario de Estudios Patrísticos de la Pontificia Universidad Católica de Chile, que tuvo lugar del 29 de agosto al 1 de septiembre de 2017. 


\section{INTRODUCCIÓN}

Más allá de las evidentes y profundas líneas de continuidad entre la filosofía de los antiguos griegos y los primeros pensadores cristianos, algunas de las doctrinas de aquellos reciben una formulación novedosa al ser asimiladas por el cristianismo. Sabido es que, entre estas cuestiones, una de las más paradigmáticas es la de la voluntad y la libertad ${ }^{1}$. Sin embargo, la historia de estos conceptos a lo largo de la Antigüedad clásica y tardía es en extremo compleja, como también la polisemia de los términos técnicos asociados a ellos según cada período, cada escuela y cada autor.

Por ello, y para evitar el riesgo de caer en generalizaciones, inevitablemente imprecisas, nos detendremos aquí en un caso puntual: la recepción de dos tratados de las Enéadas plotinianas en las obras de Gregorio de Nisa. En efecto, en el presente trabajo sugeriré que una atenta lectura de Plotino inspira en Gregorio algunas de sus tesis más originales acerca de la libertad. Sin embargo, veremos también cómo el Niseno adapta, reformula y transforma el discurso filosófico plotiniano hasta hacerlo arribar a conclusiones opuestas a aquellas sostenidas en las Enéadas.

Ya a mediados del siglo XX un estudio de Jérome Gaïth acerca de la libertad en Gregorio de Nisa señalaba la influencia de Enéadas VI 8 (39) sobre la concepción de la voluntad del Niseno, y particularmente sobre su teoría de la voluntad divina ${ }^{2}$. Efectivamente, los paralelos conceptuales y terminológicos saltan a la vista, y en lo que sigue intentaré demostrar que el inusual discurso del tratado plotiniano influye a su vez

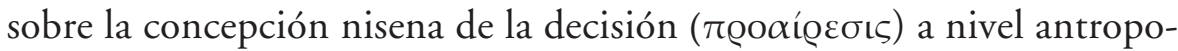
lógico. El otro tratado de Plotino que analizaremos es Enéadas I 6 (1), el primero en el orden cronológico que detalla Porfirio en su Vita Plotini ${ }^{3}$.

1 Véase, por ejemplo, los excelentes estudios de A. Dinle, The Theory of Will in Classical Antiquity (Sather Classical Lectures 48; University of California Press, Berkeley 1982), y de M. Frede, A Free Will. Origins of the Notion in Ancient Thought (Sather Classical Lectures 68; University of California Press, Berkeley 2011).

2 Cf. J. GaïTH, La conception de la liberté chez Grégoire de Nysse (Vrin, Paris 1953) 19-22. Véase también una comparación entre ambas doctrinas de la voluntad divina en L. Turcescu, Gregory of Nyssa and the Concept of Divine Persons (Oxford University Press, Oxford 2005) 41-45.

3 Cf. Porfirio, Vita Plotini 4. No obstante, es posible que Gregorio conozca el escrito de Plotino en una edición diferente a la de su renombrado discípulo fenicio. 
En el curso de su exposición sobre la belleza, Plotino menciona el símil del embellecimiento del alma como el de una estatua cuyo rostro debe ser cincelado. Gregorio hace propia esta imagen de autoplasmación de modo casi textual en algunas de sus obras, pero también le otorga en otros textos un dinamismo y unos alcances inusitados, en conformidad con su nueva concepción antropológica.

En primer lugar, entonces, se vinculará la teoría de la voluntad de lo Uno en el tratado 39 de las Enéadas de Plotino y la concepción de la voluntad divina en Gregorio de Nisa. Luego, se considerará el influjo de ambos tratados plotinianos sobre la antropología del Niseno, indagando los alcances ontológicos de la capacidad de decisión, la metáfora de la plasmación de sí mismo y la transformación ilimitada del propio ser.

\section{VOLUNTAD, LIBERTAD Y DECISIÓN EN LO DIVINO}

Es muy llamativo en la obra del Niseno el modo en que la virtualidad de la libertad humana se expande del plano meramente operativo y prác-

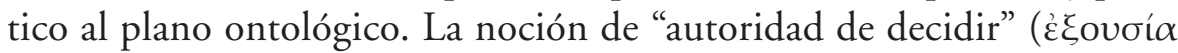

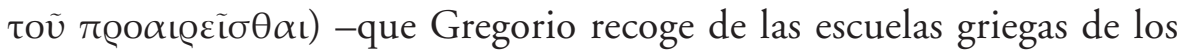
siglos anteriores y de algunos autores judíos y cristianos- se convierte en su obra de algún modo en una autoridad de $\operatorname{ser}^{4}$. Pero para comprender esta originalidad antropológica, es preciso remontarse primero a su teoría trinitaria. En el tercer libro del Contra Eunomium, Gregorio afirma la unidad entre la esencia y la voluntad divinas, con evidentes ecos plotinianos:

"Dios, por su parte, siendo un único bien ( $\hat{\varepsilon} v \omega \grave{\omega} v \dot{\alpha} \gamma \alpha \theta$ òv) en su naturaleza simple e incompuesta, mira continuamente hacia lo mismo

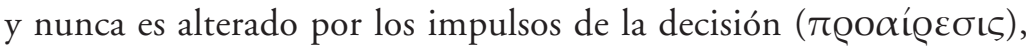

Véase J. M. Rist, "Plotinus and Christian philosophy", en L. P. Gerson (ed.), The Cambridge Companion to Plotinus (Cambridge University Press, Cambridge 1996) 399-401; J. M. Rist, "Basil's 'Neoplatonism': Its Backround and Nature”, en P. J. Fedwick (ed.), Basil of Caesarea: Christian, Humanist, Ascetic. A SixteenHundredth Anniversary Symposium (Pontifical Institute of Medieval Studies, Toronto 1981) 137-220.

4 El concepto de autoridad de decidir aparece en Gregorio DE NisA, Or cat xxxi, 1 (GNO III/4, 76.6 - 77.6). Como antecedentes, véase, por ejemplo, FILÓN DE Alejandría, Quod omnis probus liber sit 59; Alejandro de Afrodisia, De fato XI; Metodio de Olimpo, De libero arbitrio (PG 18, 264B-265A); Orígenes, Contra Celsum VIII, 72; Ps. Clemente de Roma, Homiliae VI, 9, 4-5. 
sino que siempre quiere precisamente lo que es y es absolutamente

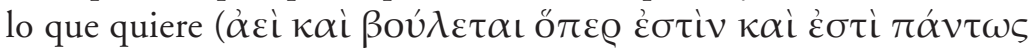

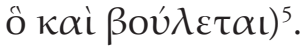

En De anima et resurrectione sostiene también que, al estar más allá

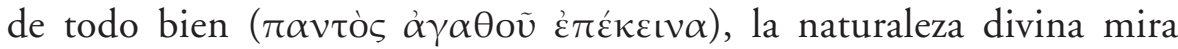

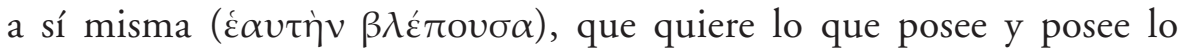

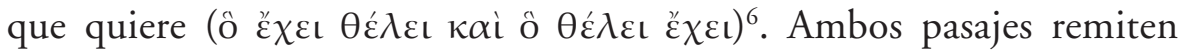
inequívocamente a afirmaciones del tratado de Plotino sobre la voluntad de lo Uno, el número 39 en el orden cronológico, que examinaremos enseguida.

En efecto, Plotino responde allí a una objeción que parece negar toda libertad a lo Uno, el principio supremo de su sistema metafísico. Por más que el maestro la tilda de discurso temerario ( toma muy en serio esta objeción y le dedica probablemente el tratado más complejo y original de las Enéadas ${ }^{7}$. Vale la pena citar completa la tesis a la que se opone.

[La naturaleza del Bien] es así como es por azar ( $\omega \varsigma \zeta \tau \chi 0 \tilde{v} \sigma \alpha)$ y no

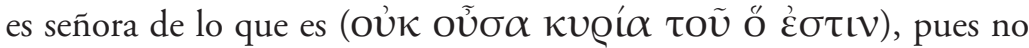
es aquello que es a partir de ella misma, ya que no posee libertad ( $\tau$ ò

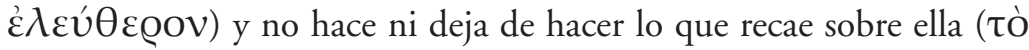

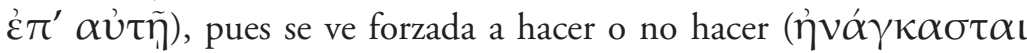

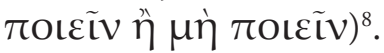

Más allá de la controversia acerca de la posible proveniencia gnóstica o cristiana de esta objeción, aún hoy muy discutida, está claro que ataca

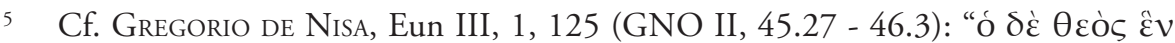

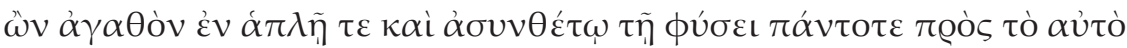

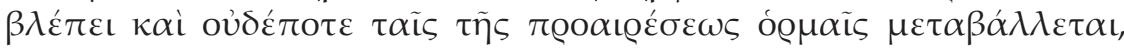

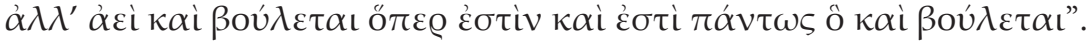

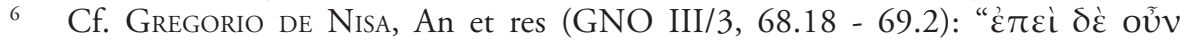

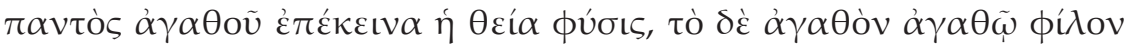

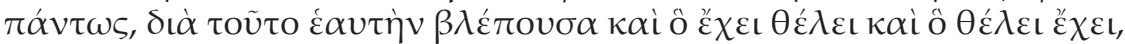

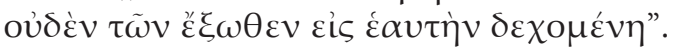

7 Véase la célebre edición del tratado y su comentario a cargo de G. Leroux, Traité sur la liberté et la volonté de l’Un (Ennéade VI.8 [39]) (Vrin, Paris 1990).

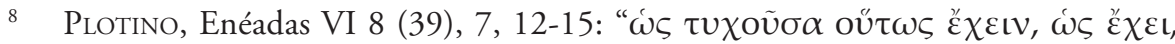

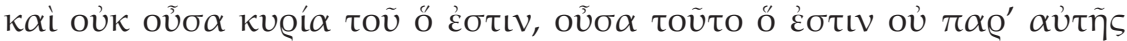

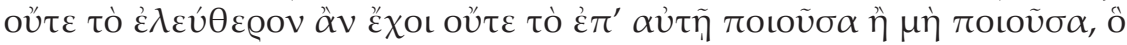

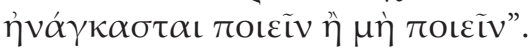


un punto neurálgico de la teoría plotiniana': si es posible compatibilizar la absoluta necesidad y perfección de los primeros principios de la realidad con alguna noción de libertad y de qué forma podrían atribuírsele tales nociones a las hipóstasis y a su proceso de emanación.

Consciente de la impropiedad del lenguaje que va a utilizar para hablar de lo Uno inexpresable, Plotino insiste, sin embargo, en atribuir a este principio las características clásicas del autogobierno (tò

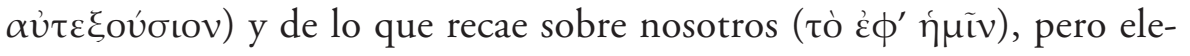
vados a un grado absoluto. Entre otras cosas afirma, como luego lo hará

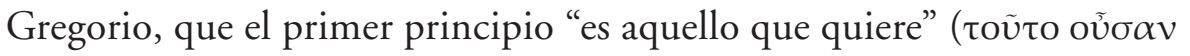
ô $\theta \varepsilon \dot{\lambda} \lambda \varepsilon \iota$ ) o que "como quiere y actúa es su propia esencia" ( $\omega \varsigma \beta$ oú $\lambda \varepsilon \tau \alpha$ í

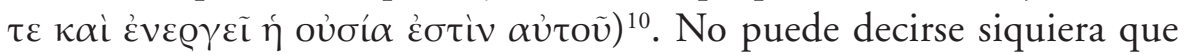

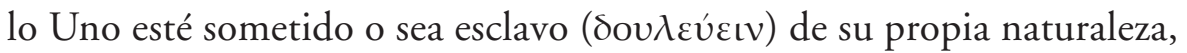
porque no hay en él dualidad entre lo que manda y lo que obedece. En él es lo mismo el ser y el obrar.

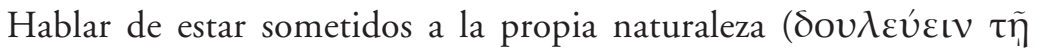
$\alpha \hat{\tau} \tau o \tilde{v} \phi \hat{\sigma} \sigma \varepsilon \iota)$ es postular dos cosas: lo sometido y aquello a lo que [está sometido]. Pero la naturaleza simple y la actividad una, que no está por un lado en potencia y por otro en acto, ¿cómo no será libre $(\pi \tilde{\omega} \varsigma$ oủk $\dot{\varepsilon} \lambda \varepsilon v \theta \varepsilon \dot{\varepsilon} \rho \alpha)$ ? Pues de ningún modo podría decirse que actúa como le es natural, como si una fuera su esencia y otra su

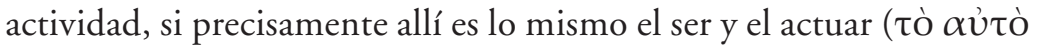

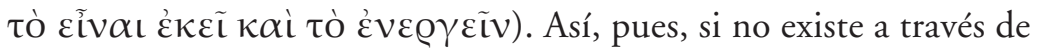
otro ni recae sobre otro, ¿cómo no será libre? ${ }^{11}$.

9 Véase G. Leroux, Traité sur la liberté..., 112-123; A. H. Armstrong. "Two Views of Freedom. A Christian Objection in Plotinus Enneads VI 8. [39]7, 11-15?”, en E. Livingstone, Studia Patristica XVII: Papers Presented to the Eighth International Conference on Patristic Studies, Oxford 1979, Part one (Pergamon, New York 1982) 397-406; J.-M. Narbonne, Plotinus in Dialogue with the Gnostics (Studies in Platonism, Neoplatonism, and the Platonic tradition 11; Brill, Leiden 2011) 129-141.

10 Cf. Enéadas VI 8 (39), 9, 42-48; 13, 8-11. Expresiones similares se repiten una y otra vez en diferentes secciones del tratado. Gregorio parece hacerse eco de ellas también al describir la creación divina, en la que la voluntad de Dios se vuelve esencia y realidad. Cf. Gregorio de NiSA, An et res (GNO III/3, 96, 6-14); Or cat xxiv, 2.

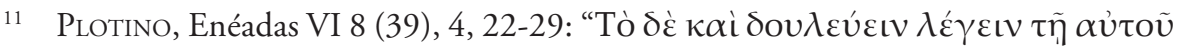

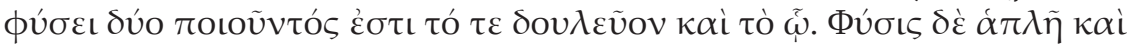

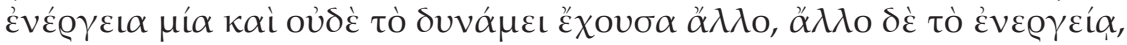

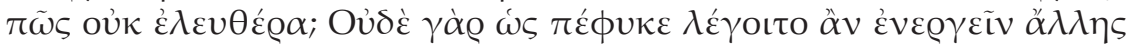


Todas estas notables licencias que Plotino se permite en su por lo demás estricto discurso negativo acerca del primer principio son para mostrar que en él se concilian todos los opuestos; en su seno libertad y necesidad coinciden. Unos capítulos más adelante el autor afirma a su

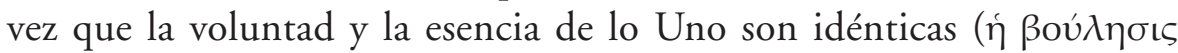

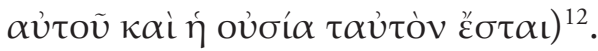

Si bien estas reflexiones de Plotino nutren la concepción gregoriana de la voluntad divina, el Niseno las modifica considerablemente, ya que las adapta a la distinción entre la esencia única y las tres hipóstasis. Si Plotino tendía a eliminar en el primer principio la diferencia entre voluntad, esencia y operación, Gregorio se preocupa por distinguir la actividad común esencial de la iniciativa propia de cada persona, aunque ellas se encuentren en perfecta armonía. Y, si bien no es tan siste-

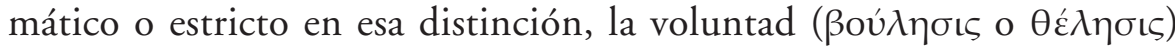
tiende a asociarse a la esencia o naturaleza divina común y la decisión

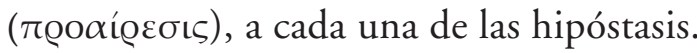

Por ejemplo, continuando con el pasaje del Contra Eunomium III citado unos párrafos más arriba, Gregorio afirma que el Verbo es llamado

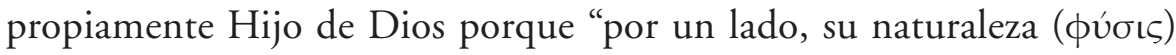

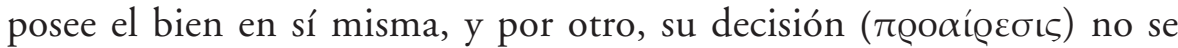
desprende de lo mejor" ${ }^{13}$. En el libro primero afirmaba ya esta distinción operativa al interior de la Trinidad, al decir que la misma comunión

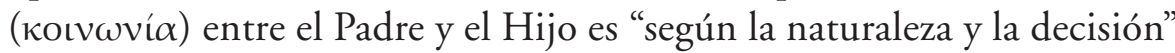

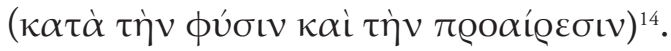

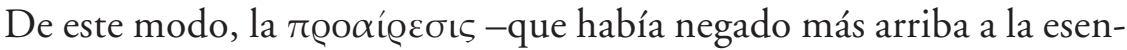
cia divina única- es atribuida a cada una de las hipóstasis. Pero entonces esta decisión no puede ser para Gregorio -aunque sí lo es para Plotinouna mera posibilidad de elegir entre contrarios, y por lo tanto una cierta imperfección. Se trata más bien del señorío de cada persona sobre su

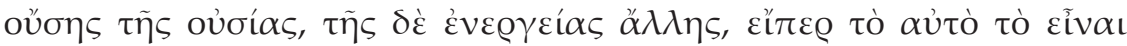

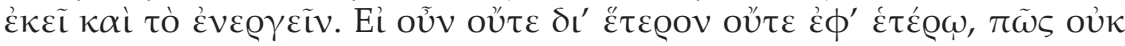

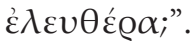

12 Cf. Plotino, Enéadas VI 8 (39), 13, 7-8. Véase también Enéadas VI 8 (39), 7, 46-54; 12, 28-37.

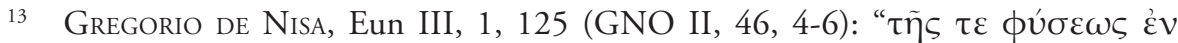

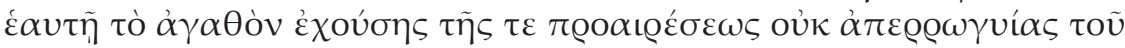

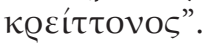

14 Cf. Eun I, 502 (GNO I, 171, 18-20). 
propia esencia. Mientras que para Plotino la libertad plena y el señorío sobre sí se logran solo al excluir toda diferencia, en la identidad absoluta de lo Uno, para Gregorio la libertad de decisión y la autoridad personal residen justamente en la diferencia, esto es, en la unicidad de cada una de las hipóstasis, distintas e irreductibles al plano esencial-ontológico. Este paso implica también una transformación del ámbito de la autoridad de elección en su antropología.

\section{LA CAPACIDAD HUMANA DE DECISIÓN. SUS ALCANCES ONTOLÓGICOS}

En efecto, Gregorio transfiere a la persona humana prerrogativas que Plotino había reservado solo a lo Uno. Y esto esclarece, creo, el motivo de aquellas inesperadas osadías antropológicas del Niseno, como cuando afirma que el autogobierno humano es "igual a Dios" (iøó $\theta \varepsilon$ cov

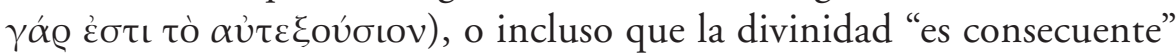

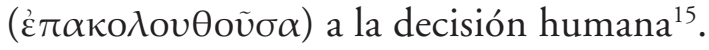

En el tratado 39 de las Enéadas se afirma que el primer principio

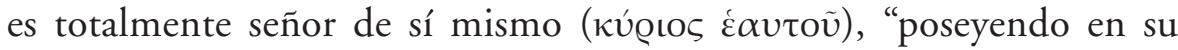

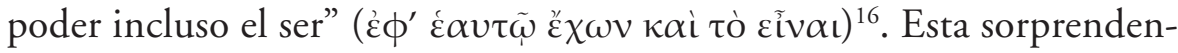
te afirmación debe leerse bajo la advertencia de la impropiedad de las expresiones a lo largo del tratado. Parece indicar que lo Uno es señor de su propio ser. Y con ello Plotino responde al "discurso temerario" de sus adversarios, que afirmaba justamente acerca de la naturaleza del Bien:

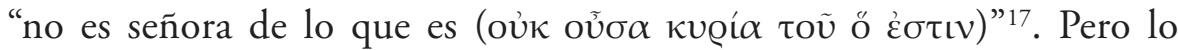
cierto es que de lo Uno no podría decirse estrictamente ni siquiera "que es", porque predicarle algo sería introducirle una dualidad ${ }^{18}$. Él mismo es anterior al ser y produce el ser en el nivel del Intelecto, la segunda hipóstasis. Entonces, más allá de las licencias del lenguaje en el tratado VI 8, puede afirmarse que en todo el sistema plotiniano el ser está siempre subordinado y depende enteramente de lo Uno.

15 Cf. Gregorio de Nisa, Mort (GNO IX, 54, 10); Vit Moys II, 86 (GNO VII/1, 58, 20-23). Para una interpretación posible de estos pasajes, véase F. BASTiTTA Harriet, "Does God 'follow' human decision? An interpretation of a passage from Gregory of Nyssa's De vita Moysis (II, 86)", en M. Vinzent (ed.), Studia Patristica LXVII - Volume 15: Cappadocian Writers; The Second Half of the Fourth Century (Peeters, Leuven 2013) 101-112.

16 Cf. Plotino, Enéadas VI 8 (39), 13, 10-11.

17 Cf. Enéadas VI 8 (39), 7, 13.

18 Véase, por ejemplo, Enéadas VI 7 (38), 38; VI 9 (9), 5. 
El Niseno, por su parte, atribuye ese señorío sobre el propio ser también a cada persona humana. De este modo, como afirma en De anima

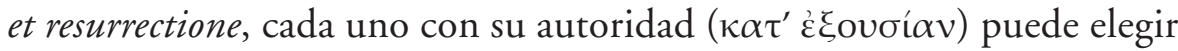

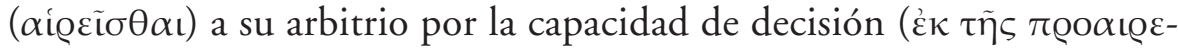

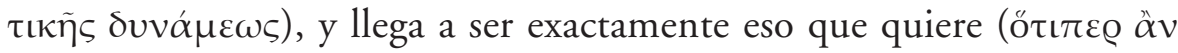

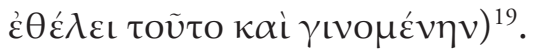

Esta última fórmula de Gregorio, que expresa la infinita virtualidad de la libertad de elección humana, se repite con mínimas variantes en gran parte de sus obras. Curiosamente, ella sigue de cerca una conjetura muy sugestiva en el tratado de las Enéadas que nos ocupa. En efecto, en un breve excursus Plotino considera el absurdo de que lo Uno pudiera

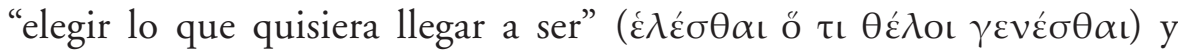
"abandonarse a sí mismo, alterar su propia naturaleza hacia otra" ( $\dot{\varepsilon} \xi \varepsilon \tilde{\varepsilon}-$

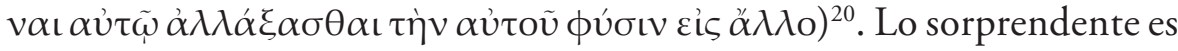
que, aunque también las tacharía de inadmisibles respecto de lo divino, el Niseno convierte estas afirmaciones en el fundamento de la libertad humana, lanzada en un progreso sin fin hacia lo infinito.

Al plantear la problemática en el plano puramente esencial, Plotino no puede evitar considerar a la diferencia exclusivamente como alteridad ontológica y, por lo tanto, como inferioridad y subordinación. Algo similar sucederá con la teología de Eunomio, a la que Gregorio se opone fervientemente ${ }^{21}$. Para Plotino, solo en la ínfima medida en que los seres humanos son la esencia (oủó́ $\alpha$ ), que él identifica con el plano del Intelecto, solo en esa medida eluden realmente la esclavitud y pueden ser llamados señores ${ }^{22}$. Pero en tanto se agrega a ellos la diferencia, que allí identifica con el cuerpo, ellos no escapan al sometimiento ${ }^{23}$. De este modo, podría decirse que la verdadera libertad solo es posible en los grados más altos de la escala metafísica, y tal vez solo en lo Uno. En

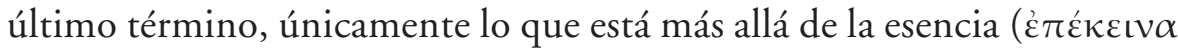
oủ $\sigma i ́ \alpha \varsigma)$, afirma Plotino, puede ser verdadera y plenamente libre, ya que

19 Cf. Gregorio de Nisa, An et res (GNO III/3, 90.21 - 91.3).

20 Cf. Plotino, Enéadas VI 8 (39), 13, 33-38.

21 Cf. Véase el fragmento de la Apologia apologiae de Eunomio de Cízico apud GREGorio DE NisA, Eun I, 151-154 (GNO I, 71.28 - 73.15).

22 Cf. Enéadas VI 8 (39), 12, 9-13.

23 Cf. Enéadas VI 8 (39), 12, 9-13. 


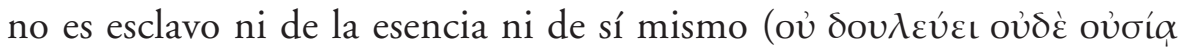
oủঠ่̀ $\dot{\varepsilon} \alpha v \tau \tilde{\omega})^{24}$.

Es interesante notar que, si bien en un sentido completamente diverso, la categoría de hipóstasis en el Niseno también se halla de algún modo "más allá de la esencia", en cuanto que es distinta e irreductible a ella. En su antropología, puesto que cada persona está más allá de la naturaleza o esencia común, la decisión personal se vuelve señora de su propio ser, capaz de modificarlo y recrearlo.

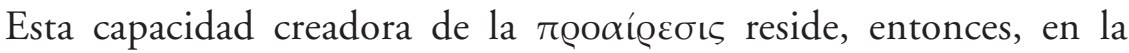
diferencia hipostática de cada ser humano, que imprime su carácter único en la naturaleza común. Ella no solo resiste los impulsos de la necesidad, sino que también puede transformar por completo el propio ser.

\section{LA PLASMACIÓN DE SÍ MISMO}

Se puede decir, siguiendo al Niseno, que al nacimiento natural de cualquier ser humano, signado por la necesidad, le sigue el nacimiento libre, obrado por la hipóstasis o persona, que despliega en su propia vida su unicidad y su diferencia. Inspirado en el pasaje joánico de Jesús con Nicodemo, en donde se habla de "nacer desde lo alto" ( $\gamma \varepsilon v \vee \eta \theta \tilde{\eta} v \alpha \iota$ $\alpha \check{\alpha} v \omega \theta \varepsilon v$ ) (cf. Jn 3, 1-8), Gregorio identifica en la Oratio Catechetica al

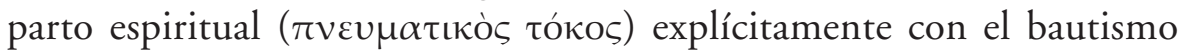
y con la vida de fe, en los cuales uno mismo es quien elige cómo nacer

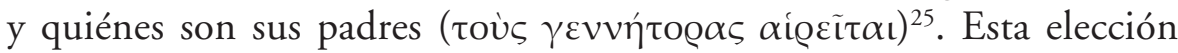
tiene hondas implicancias en la propia existencia.

Solo esta forma de ser engendrado posee por su autoridad ( $\kappa \alpha \tau^{\prime}$ $\dot{\varepsilon} \xi o v \sigma i ́ \alpha v$ ) el llegar a ser exactamente eso que haya elegido (ö $\tau \iota \pi \varepsilon Q$

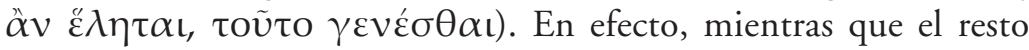
de los nacidos es constituido por el impulso de los progenitores, el nacimiento espiritual depende de la autoridad del que nace $(\tau \tilde{\eta} \varsigma$

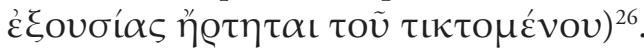

24 Cf. Enéadas VI 8 (39), 19, 12-15. Es obvia la referencia a Platón, República 509b,

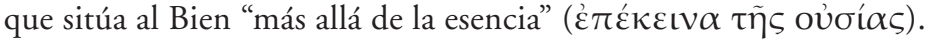

25 Cf. Gregorio de Nisa, Or Cat xxxviii-xxxix.

26 Gregorio de Nisa, Or Cat xxxviii.2 - xxxix.1 (GNO III/4, 98, 20-24): “ $\mu o ́ v o v$

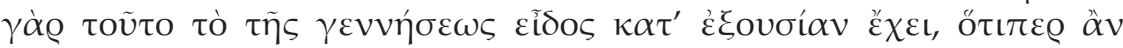

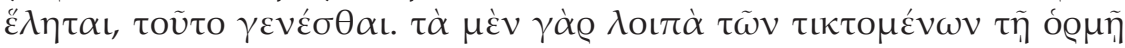


Obsérvese una vez más la llamativa semejanza de la fórmula gregoria-

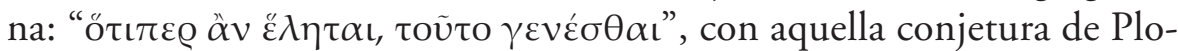

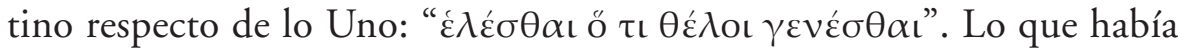
sido descartado como absurdo en referencia a lo Uno se convierte así en un privilegio propio de la autoridad de decidir humana.

En otras obras de madurez de Gregorio, como el De vita Moysis, el nacimiento personal es claramente referido al sí mismo y a la acción de

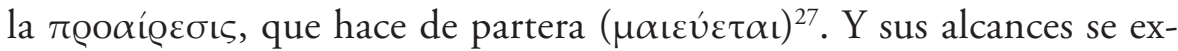
presan en imágenes aún más elocuentes.

Ser engendrado de este modo no proviene de un impulso externo, a semejanza de los que engendran corporalmente lo que surja, sino que este nacimiento se da a partir de la decisión ( Y somos en cierto modo los padres de nosotros mismos ( $\dot{\varepsilon} \alpha v \tau \tilde{\omega} v$ $\pi \alpha \tau \varepsilon ́(\varepsilon \varsigma)$, al darnos a luz a nosotros mismos tales como quere-

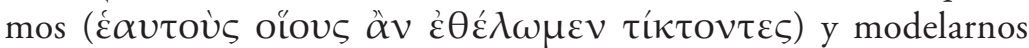
( $\delta \iota \alpha \pi \lambda \alpha \sigma \sigma o ́ \mu \varepsilon v o \iota)$ por la propia decisión hacia la forma que de-

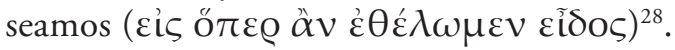

Un pasaje paralelo del In Ecclesiasten también habla de los seres humanos como sus propios padres, que se moldean y se engendran a sí mismos mediante la buena decisión (

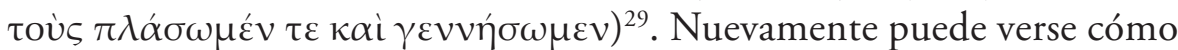
la decisión y el yo establecen una diferencia en el plano de la esencia

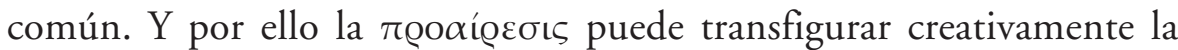
naturaleza.

Asimismo, un conocido texto de Plotino, en Enéadas I 6 (1), recurre a imágenes similares. En efecto, al tratar acerca de la belleza del alma, Plotino afirma que para descubrirla uno puede actuar como el hacedor de una estatua (

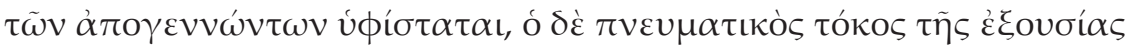

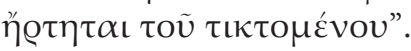

27 Cf. Gregorio de NisA, Vit Moys II, 5.

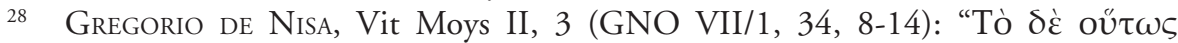

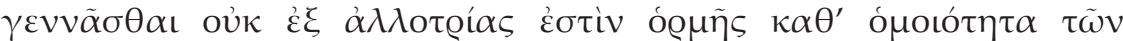

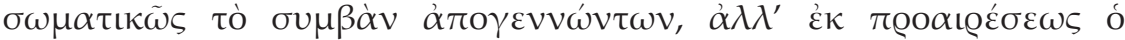

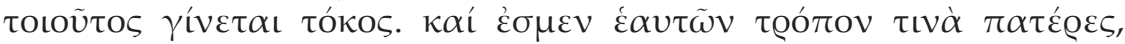

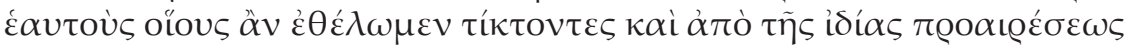

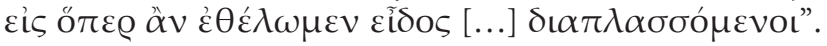

29 Cf. Gregorio de NisA, Eccl VI, 5 (GNO V, 379-381). 
lo excesivo, corrigiendo las imperfecciones, hasta que brille en uno el

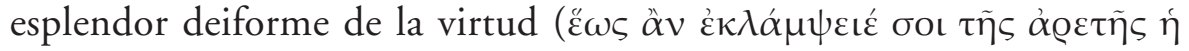

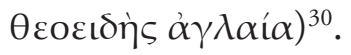

Gregorio parece recurrir más de una vez en sus obras a estas palabras de Plotino ${ }^{31}$. Es posible comprobarlo tanto por la semejanza de las descripciones como por la coincidencia de los términos. En estos textos del Niseno, lo que revela el trabajo del escultor es la imagen divina y la belleza original de la naturaleza, oscurecida por el pecado.

Sin embargo, los pasajes antes aludidos de la autocreación y autopaternidad del sí mismo en Gregorio poseen un tono diferente y van ciertamente más allá de la metáfora plotiniana. No se trata allí de quitar lo que sobra y descubrir o develar una esencia estática subyacente. Las imágenes son más dinámicas, plásticas y vigorosas, y también son más recurrentes en sus textos. Así, en una de sus últimas obras, De perfectione, el Niseno afirma: "Cada uno es el pintor de su propia vida

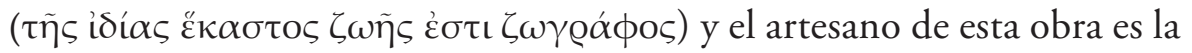

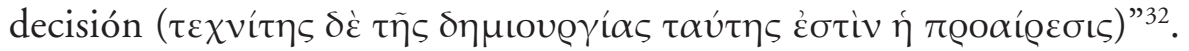
La actividad libre del "artesano" afecta a la naturaleza humana misma, modifica de algún modo su ser.

Vinculando esta metáfora con la antropología del Niseno, puede decirse que el artista y su propia vida representan la relación entre la hipóstasis y la esencia o naturaleza común. El elemento receptivo, cuyas particularidades el artesano debe conocer y aceptar para poder trabajar sobre él, se identifica con la propia naturaleza ( $\phi u ́ \sigma \iota \varsigma)$, como una especie de substrato indefinido. Ella no es un principio inferior o puramente pasivo, sino que, como imagen de la naturaleza divina infinita, contiene en sí misma la totalidad y plenitud de las perfecciones y formas de vida ${ }^{33}$. Por su parte, la realización de la obra, que manifiesta la intimidad y

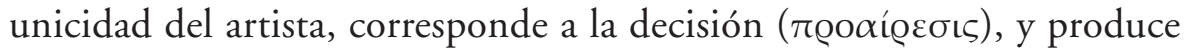
una configuración determinada, una modelación particular de aquella naturaleza, que en distintas obras de Gregorio es llamada forma, aspec-

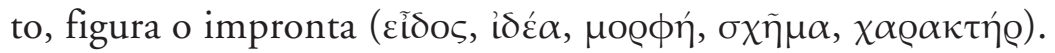

\footnotetext{
30 Cf. Plotino, Enéadas I, 6 (1), 9.

31 Véase, por ejemplo, Gregorio de NisA, Virg X-XII; Inscr II, 11, 53-54; Op hom XXX, 29-30.

32 Gregorio de Nisa, Perf (GNO VIII/1, 195.14 - 196.15).

33 Cf. Gregorio de Nisa, Op hom VIII, 5; XVI, 10-11.
} 
Para Plotino, el trabajo del escultor revelaba progresivamente la divinidad oculta e inmanente al alma, como un camino de purificación moral. Para Gregorio se trata de una modelación más plástica del yo sobre sí mismo, quien mediante su decisión se dirige hacia lo divino o hacia su opuesto, y modifica su propio ser en el proceso. En esto el Niseno está más próximo a la concepción dinámica de la libertad en Orígenes ${ }^{34}$. $\mathrm{Y}$ también a algunas expresiones de Clemente Alejandrino, quien afirma que, al asimilarse a Dios, el gnóstico "se crea y se labra a sí mismo"

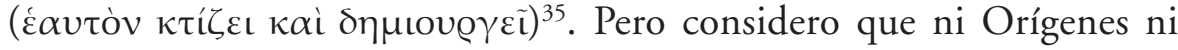
Clemente valoraban tan positivamente esta autocreatividad de cada ser humano ni habían elaborado un fundamento metafísico apropiado para ella.

Gregorio encuentra este anclaje metafísico en su propia teoría trinitaria y en la antropología consonante con ella. El binomio naturalezadecisión, expresión concreta y operante de la distinción entre esencia e hipóstasis, explicará entonces el juego entre necesidad y libertad, entre lo creado y lo creativo, entre el don y la respuesta, entre lo común y lo propio. De su íntima interacción resulta la vida de cada ser humano, pero también el destino del cosmos.

\section{UN ABSOLUTO EN DEVENIR}

En el capítulo central del De opificio hominis, su obra antropológica por excelencia, Gregorio atribuye a la imagen divina en el ser humano la plenitud de las perfecciones de Dios, afirmando que ella las realizaba en modo creatural, es decir, en el devenir ${ }^{36}$. Lo que los intérpretes no han subrayado lo suficiente es que si no fuera por esa distinción entre el modo de ser increado y el creado -podríamos decir, entre lo absoluto y lo relativo-, el hombre y Dios serían lo mismo ${ }^{37}$. Gregorio sostiene así una noción cuasisimétrica de la imagen divina en lo humano respecto de su arquetipo. La naturaleza humana vendría a ser como un Dios creado,

\footnotetext{
Véase, por ejemplo, Orígenes, De principiis II, 1, 1-3.

Cf. Clemente de Alejandría, Stromata VII, 3, 13, 3.

Cf. Gregorio de Nisa, Op hom XVI, 10-12 (ed. Forbes, 202-204).

Véase, por ejemplo, los comentarios a este texto de G. B. LADner, "The Philosophical Anthropology of Saint Gregory of Nyssa”, en Dumbarton Oaks Papers 12 (1958) 78-82 y J. ZachHuber, Human Nature in Gregory of Nyssa. Philosophical Background and Theological Significance (Brill, Leiden 2000)154-160.
} 
un Dios en devenir. Es obvio el trasfondo cristológico de estas afirmaciones en esta obra, pero eso no quita la infinita dignidad, virtualidad y plasticidad que el Niseno otorga en sí mismas a la naturaleza humana y a su libertad.

Efectivamente, describe unos capítulos antes los distintos grados de vida contenidos en la naturaleza humana como tipos de decisión o

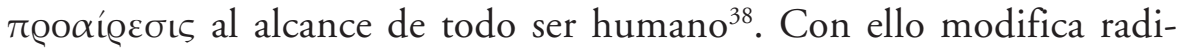
calmente la estática división de los tipos de hombres -hílicos, psíquicos y pneumáticos- entre algunas tradiciones gnósticas, y quizás también responde a la división plotiniana ${ }^{39}$. Pareciera que, según nuestro autor, el ser humano puede ir ascendiendo los distintos niveles de la naturaleza como peldaños mediante el dinamismo de su decisión. Se trata de

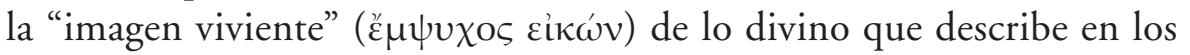
primeros capítulos ${ }^{40}$, un microcosmos animado que despliega progresivamente todas las diversas formas y perfecciones inherentes a la esencia divina misma.

Pues bien, ese mismo devenir es propuesto en el In Canticum cantico-

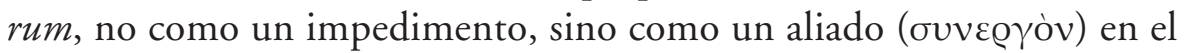
ascenso eterno hacia la perfección de $\operatorname{Dios}^{41}$. Gregorio parece completar la apropiación cristiana del mito de Proteo iniciada por Clemente y Orígenes. El proceso de transformación del propio ser es ahora constitutivo a la naturaleza humana y se abre siempre a la novedad en su ascenso sin fin hacia lo divino.

Así como en las funciones de los teatros, aunque sean los mismos actores quienes interpretan el relato que les fue asignado, sin embargo suelen aparecer otros a partir de ellos, al alternar el aspecto que los

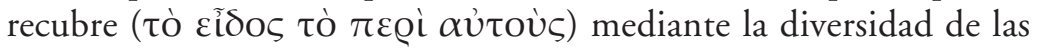

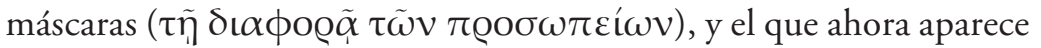
como esclavo o ignorante poco después es visto como ciudadano distinguido o soldado, y a la vez el que deja atrás la figura de un súbdito asume el aspecto de un general o también se reviste bajo

\footnotetext{
Cf. Gregorio de Nisa, Op hom VIII, 6.

Cf. Plotino, Enéadas II 9 (33), 9.

Cf. Gregorio de Nisa, Op hom IV, 1 (ed. Forbes, 126).

41 Cf. Gregorio de Nisa, Cant ViII (GNO VI, 252). Acerca de la noción de

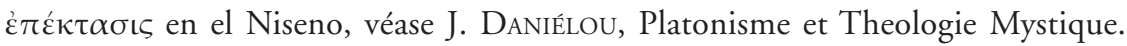
Essai sur la doctrine spirituelle de saint Grégoire de Nysse (Aubier, Paris 1944) 291-307.
} 
la forma de un rey; así también, en sus progresos hacia la virtud,

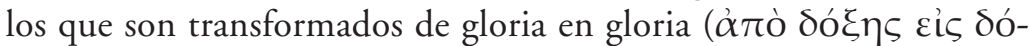
$\xi \alpha \nu \mu \varepsilon \tau \alpha \mu о \varrho \phi o u ́ \mu \varepsilon v o t)$ por el deseo de realidades más elevadas no permanecen siempre con la misma impronta $(\tau \tilde{\omega} \alpha \hat{v} \tau \tilde{\omega} \chi \alpha \varrho \alpha-$ $\kappa \tau \tilde{\eta} \varrho \iota)$, sino que, según la medida de perfección que cada uno haya sucesivamente alcanzado a través de las buenas obras, cierta impronta

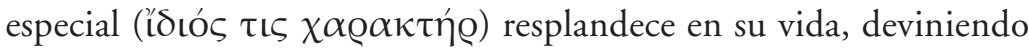

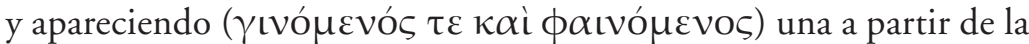
otra, a través del acrecentamiento en los bienes ${ }^{42}$.

Como puede leerse en este texto, para Gregorio el hombre está libre no solo de los condicionamientos externos, sino también de aquellos pertenecientes a su propia naturaleza. Los roles y las determinaciones de cualquier tipo no son estáticos, como el autor afirma incluso acerca de las asimetrías sociales y económicas de su tiempo ${ }^{43}$.

Imitando el osado lenguaje del tratado plotiniano, Gregorio sostiene que el ser humano no permanece siempre con la misma impronta

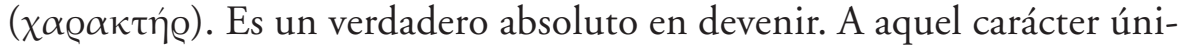

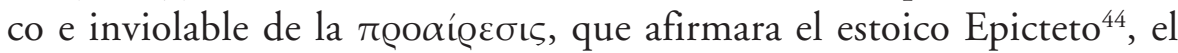
Niseno lo pone al frente de este dinamismo transformador del propio ser, "de gloria en gloria", como un eco del versículo paulino (cf. 2Cor 3, 18). Su finalidad y su perfección no son el descanso o la disolución en

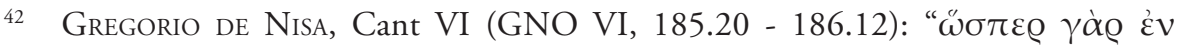

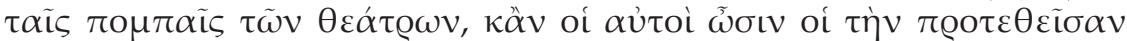

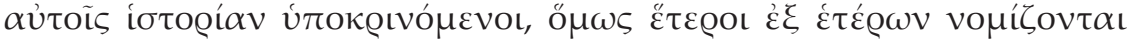

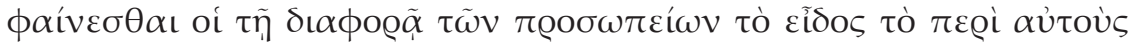

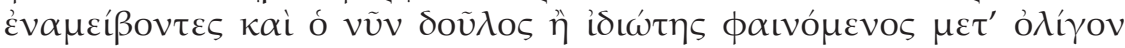

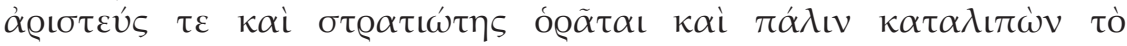

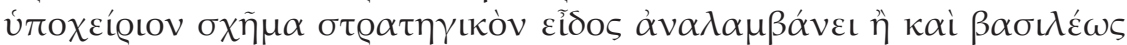

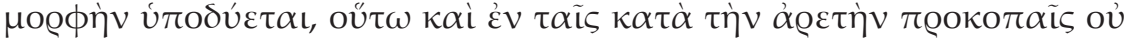

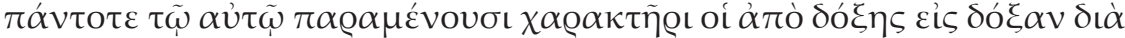

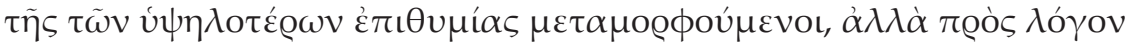

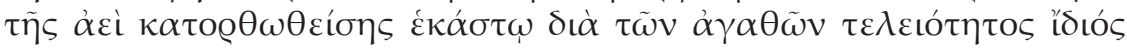

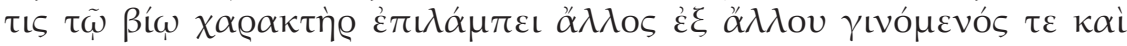

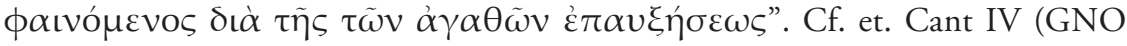
VI, 103, 15-16).

43 Para un desarrollo de esta cuestión, puede consultarse F. BASTITTA Harriet "Filiación divina, dignidad y tolerancia: de Epicteto a Gregorio de Nisa", en R. Peretó Rivas (ed.), Tolerancia: teoría y práctica en la edad media (Textes et Études du Moyen Âge 64; Brepols, Porto 2012) 13-27.

44 Cf. Ерістето, Dissertationes I, 1, 23; IV, 5, 4. 
su principio, sino este mismo impulso constante hacia adelante, en comunión cada vez más íntima con lo divino. Es el modo en que Gregorio comprende también la divinización ( $\theta \varepsilon \dot{\varepsilon} \omega \sigma \iota \varsigma, \alpha ̉ \pi 0 \theta \varepsilon ́ \omega \sigma \iota)$ del hombre. Evitando la identidad de esencia entre creador y criatura, la describe

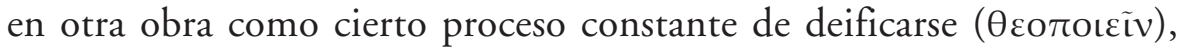
por el cual el ser humano es más y más profundamente "formado en la

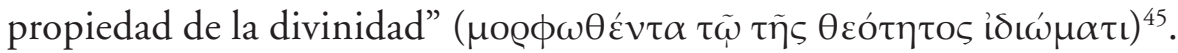

\section{CONCLUSIÓN}

Como he intentado argumentar en estas páginas, una lectura concienzuda de las audacias teológicas y terminológicas de los tratados de Plotino parece haber iluminado la especulación de Gregorio de Nisa no solo en torno a la unidad y el carácter absoluto de la voluntad divina, sino también respecto de la libertad y la decisión en cada una de las hipóstasis divinas o humanas. Los sutiles argumentos y las oscuridades del lenguaje acerca de lo Uno del maestro platónico cautivan al Niseno y se trasvasan a sus propios textos. Ambos afirman, en efecto, la absoluta soberanía y libertad del primer principio, y la coincidencia de su voluntad y de su ser. Gregorio asimila y adapta esta teoría, como hemos visto, al esquema trinitario de una esencia y tres hipóstasis.

En el plano antropológico también pueden señalarse líneas de continuidad entre Plotino y Gregorio, en especial en relación a la plasmación de sí mismo. Sin embargo, es en este campo de la libre decisión donde el Niseno se aparta con mayor claridad de su fuente. Plotino parece plantear la única vía posible de verdadera libertad en el retorno a lo Uno, que implica ciertamente la superación de las diferencias individuales. Gregorio, en cambio, pensando a partir de Plotino y más allá de él, propone una visión de la imagen divina que llega a ser aquello que elige, abierta a la virtualidad infinita de sus inherentes perfecciones. En las antípodas del sistema de Plotino, la verdadera libertad para el Niseno reside en la diferencia del sí mismo personal, que en cada ser humano puede modelar y recrear incluso su propio ser.

45 Gregorio de NisA, Beat V (GNO VII/2, 124, 16). 
